\title{
Beyond hierarchy: archaeology, common rights and social identity
}

\begin{abstract}
It is an archaeological commonplace that grazing across extensive pastures in many periods was shared, often over extended lengths of time, by kin-based communities who met there seasonally in large groups. Such explanations are richly implicit with models of social relations - there were large communities, they were made up of one or more kin groups, they shared pasture, and they had regular assemblies. How did that general framework of social structure and social relations work in practice, particularly at the level of the individual landholding? This paper explores the practical implications of a property rights approach to those questions, briefly illustrated in indicative examples drawn from the English fenlands across the longue durée. Its central contention is that the mutualities implied in the equitable, 'horizontal' governance of shared resources complemented and enriched 'vertical' hierarchies of power and status in complex societies of which they were both part.
\end{abstract}

\section{Keywords}

Common rights; property rights; collective governance; social relations

\section{Introduction}

It is an archaeological commonplace that grazing across extensive pastures in many periods was shared, often over extended lengths of time, by kin-based communities who met there seasonally in large groups. Models of Neolithic exploitation of the 4,000 square km wetlands of the English fenlands offer an indicative illustration. They are construed as having provided communal grazing for the stock of 'large numbers of people perhaps from several communities', made up of a number of kin-groups, who came together at the time of the autumn round-up in assemblies at causewayed enclosures like those at Etton and Haddenham (Pryor 1998, 364; see also Evans and Hodder 2006, 336; Evans and Serjeantson 1988, 366) (Figure 1). Interpretations based on similar collectivity are offered for Bronze Age exploitation of the fen basin, where it is suggested - there were substantial autumn gatherings of kin-based communities during which vast numbers of sheep were rounded up and sorted in large stockyards strung out along the north-western fenedge at such places as Flag Fen and West Deeping (Pryor 2001, 402-4, 416).

\section{Figure 1 about here}

Such explanations are richly implicit with models of social relations - there were large communities, they were made up of a number of kin groups, they shared pasture, and they had regular assemblies. How did that general framework of social structure and social relations work in practice, particularly at the level of the individual landholding? This paper explores the practical implications of a property rights approach to those questions whose potential for contributing to future research is briefly illustrated in indicative examples drawn from the fen basin across the longue durée.

The paper begins with a discussion of commoning in terms of property rights; it moves on to examine the implications of common rights for structures of governance; it discusses the complementary relationship between social, political and other hierarchies on the one hand and the equity that characterises the governance of shared resources on the other; it explores the implications of shared property rights for inferring greater granularity in relationships between individuals, and between individuals and their communities; and it builds on existing research demonstrating the universality across space and time of the principles of commoning to suggest their local longevity across the longue durée. 


\section{Rights of common as property rights}

Access to and the exercise of agricultural property rights enable an individual to make a reasonably predictable living, provide opportunities to generate a surplus or acquire goods, and allow personal interaction with elites through tribute, gift-giving or taxation. That is, all aspects of a stable, sustainable, farming economy depend on rights of property over land of whose antiquity there is widespread recognition among anthropologists, archaeologists and other social scientists (e.g. Ingold 1980, 82-143; Hunt and Gilman 1998; Feinman 2001; Holling 2001; Trawick 2001; Fleming 2008; Acheson 2011, 329-332). The focus of this paper is on shared or common (rather than private or public) rights of property: they are equitable, legal rights held by an exclusive group of right-holders in the restricted exploitation of a shared (frequently natural) resource with defined boundaries (Östrom 1990).

Archaeological scholarship on rights of common property has largely been undertaken in American research on collective action and public goods (e.g., Hayden and Cannon 1982; Hunt and Gilman 1998; Feinman 2000, 2001; Fargher 2009, 2010; Fargher, Espinoza, and Blanton 2011; Carballo 2013; Carballo, Roscoe, and Feinman 2014). While there is a widespread assumption in Britain of the exercise of common property rights in areas of prehistoric, Romano-British and early medieval pasture otherwise empty of settlement, the implications for social structures and relations of that premise are not generally explored (for exceptions, e.g. Fleming 2008; Herring 2008; Oosthuizen 2011).

The importance of property rights in an agricultural economy can be illustrated through the example of households who send their animals seasonally to a distant pasture. These men and women need to be sure that their animals will be safe on the journey, that their stock will be allowed to graze when they arrive, that there will be enough grazing and water for them during their stay, that they will be protected from theft or damage while there, that their journey back will be safe - and that they will reliably be able to repeat the process every year for the foreseeable future. Those objectives might be achieved by developing and maintaining relationships of trust with all the individuals and communities able to affect this aspect of their livelihoods across their lifetimes. Such personal relationships are, however, time-consuming to construct and sustain, and inherently unstable, providing neither certain protection against risk nor reliable compensation against loss. Structuring the collective exploitation of distant pastures in terms of property rights offers a practical, sustainable mitigation of those risks. The security for each individual in the articulation of access to those grasslands as socially-recognised rights of property lies in his/her reasonable expectation that the wider community will 'prevent others from interfering with his actions, provided that these actions are not prohibited in the specifications of his rights' (Demsetz 1967, 347).

Anthropologists and other social scientists define property rights in terms of bundles of legal rights of action over an object, resource or area, although the detailed conceptualization of those rights is culturally and historically variable (e.g. Demsetz 1967, 354; Alchian and Demsetz 1973, 17; Schlager and Östrom 1992; Holling 2001; Lu 2001; Carruthers and Ariovich 2004, 23-4; Stiltz 2011). In the terms of this general definition, a man who says that he owns all that he surveys - or that he has rights of property in a shared natural resource - is referring to a set of rights to use an object, area or resource in specific, clearly-defined ways that are recognised and defended by society at large. It follows that the principal aim of governance is the recognition and defence of those rights. That is to say, if property rights are demonstrated, then their governance is implied. For example, the Iron Age ringworks at Stonea Camp, in the centre of the fen basin, and at Tattershall Thorpe, on its north-west edge, have each been interpreted as sub-regional central places for seasonal assemblies whose timing was closely connected with the management and exploitation of common grazing (Malim 1992; Chowne, Girling and Greig 1986, 184-5; also Evans 2003, 268; Evans 1992, 25). If the cattle pastured on these wetlands were the physical expression of property rights shared by discrete groups of communities, then it would be reasonable to extend that interpretation by inferring that the governance of those rights was at least one object of the seasonal assemblies at these ringworks. 


\section{The implications of common property rights for structures of governance}

Can specific forms of governance be inferred from specific forms of property right? There are at least two significant problems in extrapolating forms of political structure from the archaeological demonstration of generalized rights of private or public property. The first relates to the inherent instability of such rights, which can for any number of unpredictable, idiosyncratic reasons be acquired or alienated at will, amalgamated with others, or subdivided. The second is that both can be found in societies with widely varying structures of governance, whether ruled by kings, religious leaders, war lords, clan chiefs, dictators, oligarchies, parliamentary democracies and so on. It is therefore it difficult to predict specific forms of governance from the archaeological demonstration of rights of property held either exclusively by individuals or by the entire population of a polity.

There is, by contrast, significant predictability in the structure and character of the governance of rights of common property. This is because the mutual objectives of all right-holders in a shared resource run a high risk of being affected by all, or almost all, the actions of others in relation to the resource: the equitable distribution of the resource among them, and a managed balance between the short-term maximization of its output and its long-term sustainability. Östrom, whose work on commons was awarded the Nobel prize for economics in 2009, developed the term common property regimes (hereafter CPrRs) to describe the institutions through which rights of common property are governed in pursuit of those objectives. She suggested that CPrRs are framed by seven general but distinctive design principles whatever their cultural or chronological contexts:

- the restriction of rights of common in a defined resource to an exclusive group;

- equitable rights of participation of all right-holders in the governance of the resource;

- an expectation that all right-holders will attend and participate in all meetings of a CPrR;

- decision-making by consensus;

- transparency and accountability in governance;

- records of decisions in collective oral traditions of custom and practice;

- and the principle of the 'moral economy' - that no right-holder should profit from a common right at the expense of other right-holders once his subsistence needs have been met (Östrom 1990, 90102).

The abstract nature of these principles minimizes the risk of institutional failure since they allow CPrRs to operate in and adapt to a wide variety of contexts and forms over time. While on the one hand they define predictable, orderly, normative limits to the generalized objectives at which governance must, may and must not be aimed, on the other their lack of detail allows considerable flexibility in their interpretation on the ground in response to changing external and internal environmental, cultural and social influences (Hayden and Cannon 1982, 134; Östrom 1986, 5; 1990, 90; Holling 2001, 399). For example, a particular CPrR may make changes to its regulations about who may be admitted to common rights but there will be no amendment of the overarching principle that rights of common property belong to an exclusive group; or it may agree adjustments to the boundaries of a resource, but there will be no question of their complete removal. By reserving governance of local day-to-day issues of resource allocation, regulation and management to regular assemblies of individual CPrRs, the flexibility and responsiveness of broader principles of collective governance offers the potential for a CPrR to meet its underlying objectives continuously over long periods of time. CPrRs are thus structured for survival and adaptability across the longue durée (e.g. Bourdieu 1977; Braudel 1982; Holling 2001; Folke 2006; Plielinger and Bieling 2012).

It follows that, where archaeologists have interpreted areas of land as a shared resource exploited by defined groups of individuals and/or communities, those who accessed such resources did so on the basis of legally defined rights of common property governed under a CPrR in which they were all members, and 
which had predictable operational characteristics (e.g. Fleming 2008, 85-90; Herring 2008; Oosthuizen 2011; 2013a; 2013b). To take a fenland example: the excavators of Borough Fen, a permanently occupied later Iron Age ringwork on the western fen-edge, suggested that it was a 'tribal' centre deliberately located to dominate the surrounding landscape (Malim and McKenna 1993, 61; see also Hall 1987, 26-28). Its functions, they concluded, were to oversee the management of the communal herds that grazed on the fen pastures in summer and to provide a focus for the autumn roundup. It follows from the preceding discussion that, if there was collective grazing on the fen and if it was managed from the ringwork, then Borough Fen was a centre for the governance under a CPrR of rights of common property in the wetlands. The seasonal assemblies that were held there for the collective governance of the fen and the stock that grazed it could reasonably be expected to have, for example, controlled access to rights of common, formulated regulations for its day-to-day management, agreed graduated systems of enforceable sanctions to ensure compliance, and established formal mechanisms for resolving disputes. Unless regulations were agreed from first principles each year (a time-consuming process for decisions reached by consensus), bylaws were preserved in oral traditions of custom and practice.

\section{Collective 'horizontal' governance and 'vertical' hierarchical governance}

One of the most significant implications of a common property rights approach is the characteristic equity of right-holders of otherwise different rank, status and/or wealth in the governance of a CPrR and in their access to its resources. Collective governance might thus be characterized as 'horizontal' in contrast to the 'vertical' governance of hierarchies in which access to power is directly proportional to an individual's place in the pecking order (e.g., Reynolds 1984; Östrom 1986, 1990; Feinman 2000; Stafford, Nelson and Martindale 2001, 3; Fargher and Blanton 2007). This paper does not argue that evidence for a CPrR should be taken to imply a wider prelapsarian egalitarianism, or a utopian lack of conflict, or that CPrRs were an unsophisticated precursor of 'more complex' hierarchical polities. Instead, it recognises that CPrRs did not exist in an organizational vacuum. They were an aspect of complex social organisations of which at least some features were likely to be hierarchical. Indeed, the central contention of this paper is that the specific conditions within which CPrRs are formed allow them to co-exist with, complement and thus enrich existing and/or emerging 'vertical' hierarchies of all kinds, whether social, religious, political or economic. In this CPrRs illuminate discussions of heterarchy - 'the relation of elements to one another when they are unranked, or when they possess the potential for being ranked in a number of different ways' - which usually focus on the presence of multiple hierarchies within a culture (Crumley 2005, 39; see also Ehrenreich, Crumley and Levy 1995). Shared property rights focus attention on the co-existence of 'vertical' hierarchies of all kinds with the 'horizontality' in membership and governance of CPrRs.

\section{Figures $2 a$ and $2 b$ about here}

The utility of CPrRs as an analytical tool alongside hierarchical models in archaeological explanation lies in their reminder of the importance of structured mutuality in social relations. They provide opportunities for individuals to create personal relationships characterized by reciprocal obligation with others of greater or lesser wealth, rank and/or status, through gifts or favours in kind, patronage or labour as well as through feasting, markets, religious ceremonies, family meetings and so on. Such connections between individuals strengthen and enrich the formal and informal relationships that bind holders of property rights to their communities and locate them within 'vertical' hierarchies of all kinds (e.g. Locke, Gosden and Daly 2005, 133-151; Evans and Hodder 2006, 336).

An illustration of the argument may be found in the Iron Age ringwork at Wardy Hill that, Evans (2003) suggests, was the political centre of a territory extending across the Isle of Ely. Within the ringwork, which overlooked and controlled substantial areas of shared summer pasture on the fen, there was a large space that appeared to have been used for seasonal public assemblies, including vast feasts. Such events may have been focused on the collective negotiation of 'social rights and duties ... and ... the 'performance' of tithe and tribute' by kin-based communities who came together for these purposes (Evans 2003, 255, my amendment; 
see also Pryor 1998, 351-364). If the ringwork was a territorial centre, and if access to adjacent fen grazing was restricted to exclusive groups of kin who did indeed meet there in regular assemblies, then a common property rights approach might reasonably be employed to infer further detail. For example, it might be suggested that the 'horizontal' social relations embedded in the CPrR governing the pastures braided individuals, each with other local and regional loyalties to family and kin, and to their wider communities, into a territorial polity whose summer pastures provided common grazing for them all. It offers an example of how interpretations based on models of 'vertically'-structured, hierarchical social relations - whether static or changing - might be enhanced by the additional recognition of the complexity of personal relationships implicit in 'horizontal' CPrRs: between landholders, their kin, their local communities, elites and their rulers (Figures 2a and 2b; Holling 2001; Plielinger and Bieling 2012).

\section{Structured forms of social relations implicit in rights of common property}

Three implications for the practical details of social relations between individual landholders and their communities follow.

First, a political territory is an area of land in and over which a defined group of people have exclusive rights of property of all kinds. Since common property rights connect an individual with other landholders across the largest CPrR of which he is a member, some polities and their sub-regions may be identified from rights of common linking specific communities with defined, shared natural resources (e.g. Reynolds 1984, 111). Such connections may be simplex - based on rights of common property in a single resource exploited by right-holders across an entire territory; or they may be complex, as in cases where an individual owns common rights in a range of local, sub-regional, regional and/or territorial resources. Figure 3 shows the argument in principle: an individual has rights of common (shown as a star) in - and hence participates in the governance of - common woodland in his own locality; in shared grassland with right-holders from his and a neighbouring locality; in sub-regional shared grassland with right-holders from other localities; in common regional wood pasture with right-holders from other sub-regions; and in territorial common pasture with right-holders from other regions (e.g. Reynolds 1984, 138-9).

\section{Figure 3 about here}

The definition of territories in entwined social and environmental terms of polity and shared resource has allowed the reconstruction of prehistoric, Roman and early medieval territorial units across England (e.g. Neilson 1928, 3; Joliffe 1933, 54-6; Hooke 1981, 160, 144; Jones 1987, 29-32; Ford 1987, 150; Lewis, Mitchell-Fox and Dyer 1997, 55-6; Fleming 1998, 56; Herring et al. 2011). There is, for instance, general agreement that medieval CPrRs around the edges of the East Anglian fen basin, each focused on an exclusive area of wetland grazing, preserved the geographies of early Anglo-Saxon polities whose territories included both those extensive commons and the uplands from which they were exploited (Neilson 1920, xlix-Iviii; Roffe 1993, 83; Roffe 2005, 268; Oosthuizen 2016a; Figure 4). That is, if it is possible to identify areas subject to rights of common it may also be possible to identify the territorial units within which they lay.

\section{Figure 4 about here}

The second implication is illustrated in the consensus that British political identity from the middle of the first millennium BC until at least the later Anglo-Saxon period was conceptualized in terms of control of defined territories by groups of (real or constructed) kin claiming descent from a (real or mythical) common ancestor (Neilson 1920, 43-7, 68; Charles-Edwards 1972, 3-4; Gosden 1985; Härke 1997, 137; Cunliffe 2010, 30, 605; Charles-Edwards 2014). Reynolds has suggested that it is not surprising that such polities were so often rationalized in terms of 'communities of common descent' since the mutual obligations, responsibilities and rights integral to CPrRs, as well as their shared oral traditions of custom and practice, are also aspects of relationships between kin $(1983,381)$. In other words, intersections between territoriality, landholding, rights of common, and collective governance that are visible in CPrRs may in many cases have been mediated in terms of kinship. 
This brings us to the third implication, embedded in the characteristic limitation of rights of common property to an exclusive group. It can be exemplified in early medieval Britain - and perhaps much earlier - in the restriction of access to property rights to those who satisfied conditions of status. Applicants were required to be members of the kin group, whether that status was inherited or acquired, and they had to be of free status, whether inherited or acquired (e.g. Charles-Edwards 1972, 5-9; Gosden 1985, 481; Härke $1997,137)$. Access to rights of property was a mark of both individual and wider social status, however illdefined the lower boundaries of either might be. Property acquired in this way was made up of two inextricably interlocked components: an independently-cultivated landholding and rights of common in shared resources. It was subject to concomitant legal obligations to the territory as a whole: the expectation of participation in collective governance at all levels, membership of a communal militia, and contributions of characteristic public renders, services and money payments. Faith has emphasised the degree to which 'the idea of 'law-worthiness', of entitlement to participate in the system, was of paramount importance to personal status' in early medieval England $(1997,117)$. Gosden's epigram - 'a political system in the idiom of kinship' - describes a similar case for late prehistoric Britain $(1985,480)$. Both indicate that, where there is archaeological evidence for shared rights in natural resources, the possibility might also be considered of a minimum social position for landholders whose social identity was based at least in part on their access to rights of common property, participation in the collective governance of shared resources, mutual obligations and reciprocities within a CPrR, and legal responsibilities exercised across the polity as a whole.

\section{Common rights and the longue durée}

Four aspects of CPrRs suggest that they have the potential to persist for considerable periods. First, the individual lifespans of their members do not limit the longevity of a CPrR unless it is specifically constructed in that way. Second, the principles on which CPrRs are based are so generalized that they allow sufficient flexibility to adapt to the detail of almost any changing circumstance. Third, this form of governance is inherently conservative and risk averse since common rights are legal rights whose amendment requires the collective assent of all right holders. And finally, because the values of reciprocity and mutuality that underpin CPrRs are also those that characterise relationships between kin, they are 'systems of social behavior which provide a framework over the longue durée within which the individual can operate [while] safeguarding ... the structure of the community, and thus its power to reproduce itself' (Cunliffe 2010, 681; see also Bourdieu 1977; Holling 2001, 398).

Palynological evidence of the stability from prehistory into the middle ages of mosaics of grassland species on areas of long-standing common pasture illustrates the longevity of some CPrRs. On the Cheviot Hills, for example, the character of high quality, species-rich grassland collectively grazed from the Iron Age until the mid-eighteenth century remained unchanged across at least two millennia (Davies and Dixon 2007, 29, 38). So too, 'the vegetation of [Bodmin] moor seems to have been very similar [from the Iron Age] throughout the first millennium $A D$, with predominantly pastoral land use, plus some grassland management for hay' (Gearey, Charman and Kent 2000, 56, my addition). Because environmental systems are not naturally static, such stability can only have been the result of continuous, long-term and deliberate management by the CPrRs that governed these commons. Such examples illustrate O'Connor's proposition that 'in at least some cases, that [long-term] constancy was deliberate, and what we are detecting (and largely ignoring) is quite deliberate management of the landscape to maintain that landscape as it ought to be' $(2009,11, \mathrm{my}$ addition). In the case of pasture managed as a shared resource, that management is most likely to have been undertaken within a CPrR. Similar long-term continuities have been identified across all periods and cultures (e.g. Netting 1976; Östrom 1990, 58-102; Oosthuizen 2011; 2013b, 24-43; Plielinger and Bieling 2012, 126145 and 242-260).

The evidence for the persistence for centuries or even millennia of structures of 'horizontal' governance over shared natural resources is not surprising, since the generalized principles on which CPrRs are structured underpin their elastic capacity to adapt to both extrinsic and intrinsic influences and processes, as 
well as to transformations in the 'vertical' social, political and economic hierarchies that they complemented. They exemplify Hollings' widely adopted vision of how 'a healthy social-ecological system can invent and experiment, benefitting from inventions that create opportunity while it is kept safe from those that destablise the system because of their nature or excessive exuberance' $(2001,399)$. The adaptability of CPrRs for the collective governance, management and exploitation of fenland resources may explain both the long-term ecological stability of the region and consistent evidence over six millenia for shared grazing on its pastures despite consistent, sometimes substantial, changes in material culture and social organisation (Figures $1 \mathrm{~b}$ and 4, Illustration 1). Although the causewayed enclosures of the Neolithic fenland described above eventually fell out of use, archaeologists suggest that commoning persisted and assemblies for its governance moved to Bronze Age stockyards - and, when they, too, became redundant, to Iron Age ringworks. By the early middle ages assemblies continued to be held on commons or near their boundaries as, for example, at a lost site called Modich 'deep into the marshy no-man's-land between the island of Ely and the northern group of villages about Wisbech' (Miller 1951, 32).

Scepticism about such continuity is predicated on disruptions to social stability, most often (in archaeological terms) expressed in changes in material culture. How might breaks in the collective governance of rights of common property be explained? First, an hiatus where there is no ecological evidence of disruption to the character of a natural resource might be explained in terms of the takeover of a continuing CPrR by a completely new membership. It requires the transfer, within a brief period and without interruption to the $\mathrm{CPrR}$, of all existing rights of property in the resource to a set of individuals who had not previously been involved in the CPrR and who were ignorant of its workings (for example, in the displacement of an existing population by incomers). This is a particularly complicated explanation. The success of the model depends on the efficient transmission from the original group to its successors within a short length of time of all existing institutional knowledge, built up over a long period and held in oral traditions of custom and practice, including such key practical elements as the finer detail of territorial boundaries and the subtle knowledge of local soils, topography, drainage and growing conditions required for successful day-to-day management of a resource.

An alternative explanation might propose that all existing CPrRs were abolished and replaced by entirely new ones over the same resources. That is similarly complicated explanation. It depends on the complete loss of all property rights including the cessation of all common rights, lack of any memory of previous CPrRs, and then their later re-emergence. Loss of all institutional memory would involve at least a generation of abandonment to allow not only for the location and boundaries of a resource to be forgotten but also, more importantly, for the detailed arrangements of the previous CPrR also to be forgotten. A generation of desertion is long enough for woodland to regenerate on previously open land or (in the case of fens) for succession to woodland in some of its drier areas. By and large, there is relatively little evidence of such abandonment across Britain at any time after the middle of the first millennium BC.

This is not to say that such explanations are never viable. However, where evidence to support them is lacking, it makes sense to adopt the most straightforward interpretation of the absence of that evidence that rights of common property and the CPrRs that governed them were, more often that not, characterized by continuity as they adapted to new circumstances across the longue durée (Oosthuizen 2016b). There is an intuitive sense to this conclusion since agricultural subsistence from one year to the next depended at least in part on the continuous exploitation of such resources.

\section{Conclusion}

The preceding pages have argued that specific aspects of social organisation can be predicted where there is evidence that individuals or communities owned and exercised rights of common property over a natural resource - mostly importantly, that such collective rights were governed within a CPrR that had the potential to exhibit considerable continuity across the longue durée. The distinctive characteristics of CPrRs offer further granularity in predicting social relations and social identity: those holding rights of common property 
can be expected to have been active, equal participants in the collective governance of their rights; their equitable rights of access to and exploitation of the resource they governed can similarly be inferred; since the mutualities that are integral to collective governance are so similar to the rights and responsibilities owed to and from kin, they predicate enriched models of social relationships across such 'horizontal' forms of governance whose members may otherwise have been of different rank, wealth and/or status; governance of CPrRs was undertaken through regular, often seasonal, assemblies frequently accompanied by feasting, markets, religious ceremonies, family meetings and so on; and that access to rights of property and their concomitant obligations were marks of social distinction that implied a minimum status for landholders.

If attendance and participation in 'horizontal' CPrRs were integral to social identity, then common property rights and their governance offer rich possibilities for exploring the detail not only of relationships between households and their wider communities in the governance of shared resources, but also of their complementary contribution to relationships across 'vertical' social, political and hierarchies in the wider landscape.

Susan Oosthuizen

University of Cambridge Institute of Continuing Education

\section{Acknowledgements}

This paper is based on a paper given at the University of Glasgow in September 2015 at the annual conference of the European Association of Archaeologists. I am grateful to Mr Peter Herring and other participants for their helpful comments, as well as those of the anonymous referees. Figures 1 and 4 were drawn by Mrs Sarah Wroot.

\section{References}

Acheson, J. 2011. Östrom for anthropologists. International Journal of the Commons 5, 2: 319-339.

Alchian, A. and H. Demsetz. 1973. The property right paradigm. Journal of Economic History 33: 16-27.

Bailey, M. 2010. Beyond the Midland field system: the determinants of common rights over the arable in medieval England. Agricultural History Review 58, 2: 153-71.

Bourdieu, P. 1977. Outline of a Theory of Practice. Cambridge: Cambridge University Press.

Braudel, F. 1982. On History. Chicago: University of Chicago Press.

Carballo, D., ed. 2013. Cooperation and Collective Action. Boulder: University Press of Colorado.

Carballo, D., P. Roscoe, and G. Feinman. 2014. Cooperation and collective action in the cultural evolution of complex societies. Journal of Archaeological Method and Theory 21: 98 - 133.

Carruthers, B. and L. Ariovich. 2004. The sociology of property rights. Annual Review of Sociology 30: 23-46.

Charles-Edwards, T. 1972. Kinship, status and the origins of the hide. Past and Present 56: 3-33.

Charles-Edwards, T. 2014. Wales and the Britons, 350-1064. Oxford: Oxford University Press. 
Chowne, P., M. Girling, and J. Greig. 1986. Excavations at an Iron Age defended enclosure at Tattershall Thorpe, Lincolnshire. Proceedings of the Prehistoric Society 52: 159-88.

Crumley, C. 2005. Remember how to organise: heterarchy across disciplines. In Nonlinear Models for Archaeology and Anthropology, eds. C. Beekman and W. Baden, 35-50. Aldershot: Ashgate.

Cunliffe, B. 2010. Iron Age Communities in Britain. London: Routledge.

Davies, A. and P. Dixon. 2007. Reading the pastoral landscape: Palynological and historical evidence for the impacts of long-term grazing on Wether Hill, Ingram, Northumberland. Landscape History 29: 35-47.

Demsetz, H. 1967. Toward a theory of property rights. American Economic Review 57: 347-359.

Ehrenreich, R., C. Crumley, and J. Levy, eds. 1995. Heterarchy and the Analysis of Complex Societies. Arlington: Archaeological Papers of the American Anthropological Association, Number 6.

Evans, C. 1992. Commanding gestures in lowlands: the investigation of two Iron Age Ringworks. Fenland Research 7: 16-34.

Evans, C. 2003. Power and island communities: Excavations at the Wardy Hill ringwork, Coveney, Ely. East Anglian Archaeology 103.

Evans, C. and D. Serjeantson. 1988. The backwater economy of a fen-edge community in the Iron Age: the Upper Delphs, Haddenham. Antiquity 62, 235: 360-170.

Evans, C. and I. Hodder. 2006. Woodland Archaeology. Neolithic sites at Haddenham. Cambridge: McDonald Institute Monographs.

Faith, R. 1997. The English Peasantry and the Growth of Lordship. Leicester: Leicester University Press.

Fargher, L. F. 2009. A comparison of the spatial distribution of agricultural and craft specialization in five state-level societies. Journal of Anthropological Research 65: $353-387$.

Fargher, L. F. 2010. Egalitarian ideology and political power in preHispanic central Mexico: The case of Tlaxcallan. Latin American Antiquity 21: 227 - 251.

Fargher, L. F., V. Espinoza, and R. Blanton. 2011. Alternative pathways to power in late postclassic highland Mesoamerica. Journal of Anthropological Archaeology 30: 306 - 326.

Feinman, G. 2000. Political hierarchies and organizational strategies in the Publoan southwest. American Antiquity 65: $449-470$.

Feinman, G. 2001. Mesoamerican political complexity. The corporate-network dimension. In From Leaders to Rulers, ed. J. Haas, 151-175. New York: Kluwer Academic.

Fleming, A. 1998. The quest for territorial pattern. In The Archaeology of Landscape, ed. P. Everson and T. Williamson, 42-66. Manchester: Manchester University Press.

Fleming, A. 2008. The Dartmoor Reaves. Investigating Prehistoric Land Divisions. Oxford: Windgather.

Folke, C. 2006. Resilience: The emergence of a perspective for social-ecological systems analysis. Global Environmental Change 16: 253-267.

Ford, W. 1987. Some settlement patterns in the central region of the Warwickshire Avon. In English Medieval Settlement, ed. P. Sawyer, 143-163. London: Arnold.

Gearey, B., D. Charman, and M. Kent. 2000. Palaeoecological evidence for the prehistoric settlement of Bodmin Moor, Cornwall, Southwest England. Part II: Land use changes from the Neolithic to the present. Journal of Archaeological Science 27: 493-508.

Gosden, C. 1985. Gifts and kin in early Iron Age Europe. Man n.s. 20: 475-493. 
Hall, D. 1987. The Fenland Project, Number 2. Cambridgeshire Survey: Peterborough to March. East Anglian Archaeology 35.

Härke, H. 1997. Early Anglo-Saxon social structure. In The Anglo-Saxons from the Migration Period to the Eighth Century: An Ethnographic Perspective, ed. J. Hines, 125-60. Woodbridge: Boydell and Brewer.

Hayden, B. and A. Cannon. 1982. The corporate group as an archaeological unit. Journal of Anthropological Archaeology 1: 132-158.

Herring, P. 2008. Commons, fields and communities in prehistoric Cornwall. In Recent Approaches to the Archaeology of Land Allotment, ed. A. Chadwick, 70-95. Oxford: British Archaeological Reports British Series 1875.

Herring, P., A. Preston-Jones, C. Thorpe, and I. Wood. 2011. Early medieval Cornwall. Cornish Archaeology 50: 263-286.

Holling, C. 2001. Understanding the complexity of economic, ecological and social systems. Ecosystems 4: 390-405.

Hooke, D. 1981. Anglo-Saxon Landscapes of the West Midlands: The Charter Evidence. Oxford: British Archaeological Reports British Series 95.

Hunt, R. C. and A. Gilman, eds. 1998. Property in Economic Context. Lanham: Society for Economic Anthropology, University Press of America.

Ingold, T. 1980. Hunters, Pastoralists and Ranchers: Reindeer Economies and Their Transformations. Cambridge: Cambridge University Press.

Joliffe, J. 1933. Pre-Feudal England. The Jutes. Oxford: Oxford University Press.

Jones, G. 1987. Multiple estates and early settlement. In English Medieval Settlement, ed. P. Sawyer, 9-34. London: Arnold.

Lewis, C., P. Mitchell-Fox, and C. Dyer. 1997. Village, Hamlet and Field. Manchester: Manchester University Press.

Locke, G., C. Gosden, and P. Daly. 2005. Segsbury Camp. Excavations in 1996 and 1997 at an Iron Age Hillfort on the Oxfordshire Ridgeway. Oxford: Institute of Archaeology University of Oxford.

Lu, F. E. 2001. The common property regime of the Huaorani Indians of Ecuador: Implications and challenges for conservation. Human Ecology 29, 4: 425-447).

Malim, T. 1992 . Excavations and site management at Stonea Camp, Wimblington. Fenland Research 7: 2734.

Malim, T. and R. McKenna. 1993. Borough Fen Ringwork: Iron Age fort. Fenland Research 8: 53-62.

Miller, E. 1951. The Abbey and Bishopric of Ely. Cambridge: Cambridge University Press.

Neilson, N. 1920. A Terrier of Fleet, Lincolnshire. London: British Academy.

Neilson, N. 1928. The Cartulary and Terrier of the Priory of Bilsington, Kent. London: British Academy.

Netting, R. 1976. What Alpine peasants have in common: Observations on communal tenure in a Swiss village. Human Ecology 4, 2: 135-146.

O'Connor, T. 2009. Culture and environment: Mind the gap. In Land and People, ed. M. J. Allen, N. Sharples, and T. O'Connor, 11-18. Oxford: Oxbow Books.

Oosthuizen, S. 2011. Archaeology, common rights, and the origins of Anglo-Saxon identity. Early Medieval Europe 19: 153-181. 
Oosthuizen, S. 2013a. Beyond hierarchy: The archaeology of collective governance. World Archaeology 45: 714-29.

Oosthuizen, S. 2013b. Tradition and Transformation in Anglo-Saxon England: Archaeology, Common Rights and Landscape. London: Bloomsbury Academic.

Oosthuizen, S. 2016a. Culture and identity in the early medieval fenland landscape. Landscape History 37, 1: 5-24.

Oosthuizen, S. 2016b. Review article: Recognising and moving on from a failed paradigm: The case study of agricultural landscapes in Anglo-Saxon England c.400-800AD. Journal of Archaeological Research 24, published first online November 2015.

Östrom, E. 1986. An agenda for the study of institutions. Public Choice 48: 3-25.

Östrom, E. 1990. Governing the Commons. The Evolution of Institutions for Collective Action. Cambridge: Cambridge University Press.

Plielinger, T., and Bieling, C., eds. 2012. Resilience and the Cultural Landscape. Cambridge: Cambridge University Press.

Pryor, F. 1998. Etton: Excavations at a Neolithic, Causewayed Enclosure near Maxey, Cambridgeshire, 19827. Swindon: English Heritage.

Pryor, F. 2001. The Flag Fen Basin: Archaeology and Environment of a Fenland Landscape. Swindon: English Heritage.

Reynolds, S. 1983. Medieval Origines Gentium and the community of the realm. History 68, 224: 375-390.

Reynolds, S. 1984. Kingdoms and Communities in Western Europe. Oxford: Clarendon Press.

Roffe, D. 1993. On Myddan Gyrwan Fenne: Intercommoning around the island of Crowland. Fenland Research 8: 80-86.

Roffe, D. 2005. The historical content. In Anglo-Saxon Settlement in the Siltland of Eastern England, A. Crowson, T. Lane, K. Penn and D. Trimble, 264-288. Heckington: Lincolnshire Society for Archaeology and History.

Schlager, E., and Östrom, E. 1992. Property-rights regimes and natural resources: A conceptual analysis. Land Economics 68, 3: 249-62.

Stafford, P., J. Nelson, and J. Martindale. 2001. Introduction to Law, Laity and Solidarities. Essays in Honour of Susan Reynolds, ed. P. Stafford, J. Nelson, and J. Martindale, 1-11. Manchester: Manchester University Press.

Stilz, A. 2011. Nations, states, and territory. Ethics 121: 572-601.

Trawick, P. 2001. Successfully governing the commons: principles of social organisation in an Andean irrigation system. Human Ecology 29, 1: 1-25. 


\section{Figures and captions}

Figure 1 The location of regions and sites mentioned in the text.

Figure 2a 'Vertical' hierarchical governance in which there is a direct relationship between individual wealth and status and access to power

Figure $2 b \quad$ Complementarity between equitable 'horizontal' governance through CPrRs and 'vertical' governance exercised through hierarchies

Figure 3 Complexity of nested rights of common and membership across a number of CPrRs, from local to territorial

Figure 4 Clusters of medieval intercommoning communities fossilise the territories of early medieval folk-groups that predated the emergence of manors. The head of each pin shows the location of the medieval settlement in each community, and the end of the pin the area in which land-holders within each community had rights of common. 